\title{
Review and Survey of Compact and Broadband Microstrip Patch Antenna
}

\author{
Shweta Bhatnagar \\ Dehradun Institute of Technology \\ Dehradun (INDIA)
}

\author{
Ajay Singh \\ Dehradun Institute of Technology \\ Dehradun (INDIA)
}

\author{
S.C. Gupta, PhD. \\ Dehradun Institute of \\ Technology Dehradun (INDIA)
}

\begin{abstract}
Today Communication devices support several applications which require higher bandwidth; such as mobile phones these days are getting thinner and smarter but many application supported by them require higher bandwidth, so microstrip antenna used for performing this operation should provide wider bandwidth as well as their size should be compact so that it should occupy less space while keeping the size of device as small as possible. In this paper a review of different techniques used for compact and broadband microstrip patch antenna is given.
\end{abstract}

\section{INTRODUCTION}

As the size of communication devices are getting smaller and smaller day-by-day, so the microstrip patch antenna used in these devices should have compact size, as the bandwidth of microstrip patch antenna depends upon the size of antenna, so smaller the antenna size, smaller is the bandwidth achieved. For enhancing the bandwidth by keeping the small size different techniques like Shorted Patch, Stacked Shorted Patch, Slot-Loading Technique and Slotted Ground Plane Technique are used by manufacturers. All these techniques are further discussed in this review paper.

\section{COMPACT AND BROADBAND MICROSTRIP ANTENNA WITH SHORTED PATCH}

In shorted patch technique radiating patch of microstrip antenna is shorted by a shorting pin through ground via substrate material. This short circuit may be complete, by wrapping a copper strip around the edge of the antenna, or it may be simulated by shorting post [3]. It is easy to construct a shorting post than wrapping a copper strip around the edge. Position of shorting pin depends on the application. A compact size microstrip antenna configuration [1] is given below:

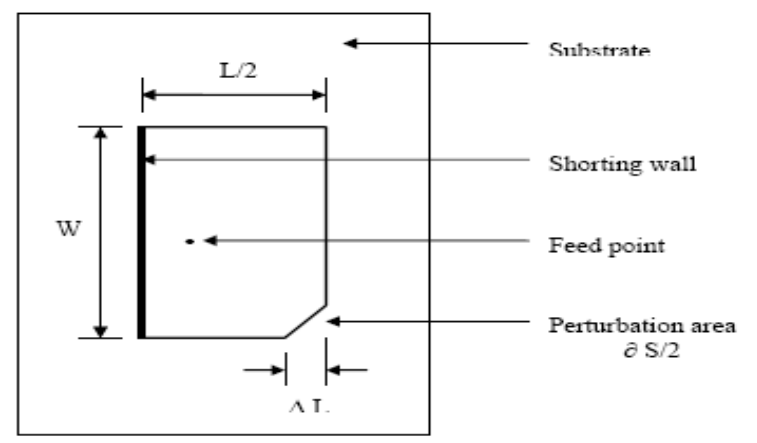

Fig 1: Configuration of microstrip antenna with shorted pin [1]

This configuration is design for GPS antenna which works at frequency $1.575 \mathrm{GHz}$. Size reductions of $24.6 \%$ is achieved as compare to conventional microstrip patch antenna.
Another design of a compact and broadband microstrip patch antenna for the IMT-2000 mobile handset [2] application with single shorting posts yields bandwidth of $17.8 \%$ at frequency range of $1.862-2.225 \mathrm{GHz}$.

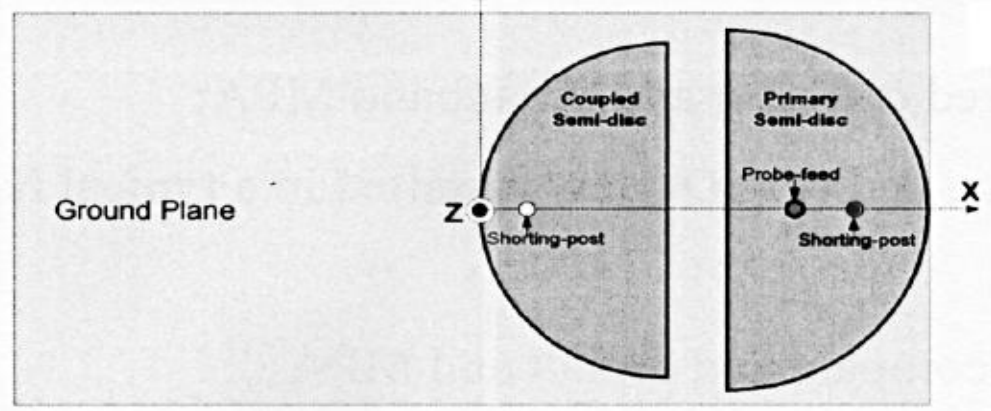

Fig 2: Microstrip patch antenna with single shorting posts [2]. 


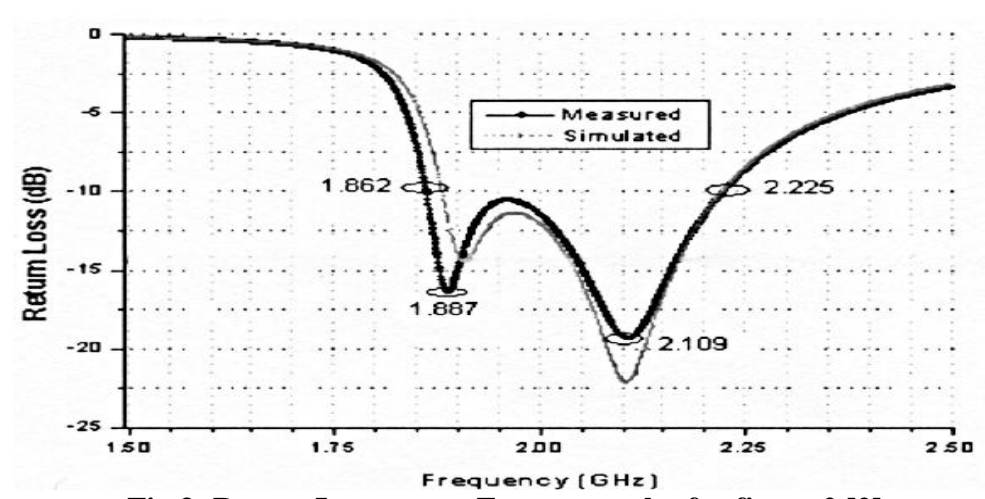

Fig 3: Return Loss versus Frequency plot for figure 2 [2].

Dimension of this proposed antenna is $44.4 \mathrm{~mm}$ (length) $\times$ $37.8 \mathrm{~mm}$ (width) $\times 7 \mathrm{~mm}$ (thickness) [3]. Antenna with this dimension is suitable of IMT-2000 mobile handset.
Another configuration of rectangular microstrip patch antenna with shorting post is shown in figure 4 and overall size of the antenna is significantly reduced by single shorting posts.
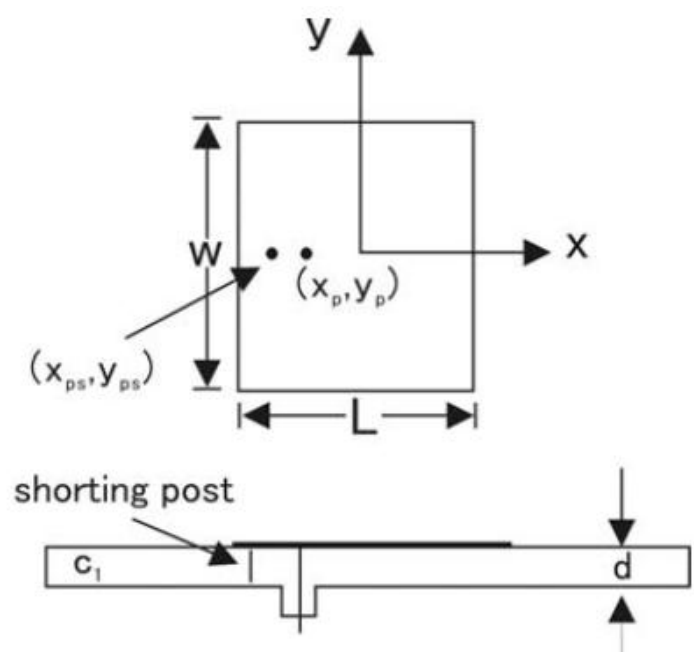

Fig 4: Rectangular microstrip antennas loaded with shorting post [4].

Another configuration is probe-fed shorted patch antenna operating at dual band shown in fig 5 [5]. It's operated on dual frequency band 1.8 and $2.45 \mathrm{GHz}$ and yields bandwidth of
$17.4 \%$ for lower operating band which covers DCS and 3\% for upper frequency band which covers ISM band with rectangular patch of dimension $36 * 16 \mathrm{~mm}^{2}$.

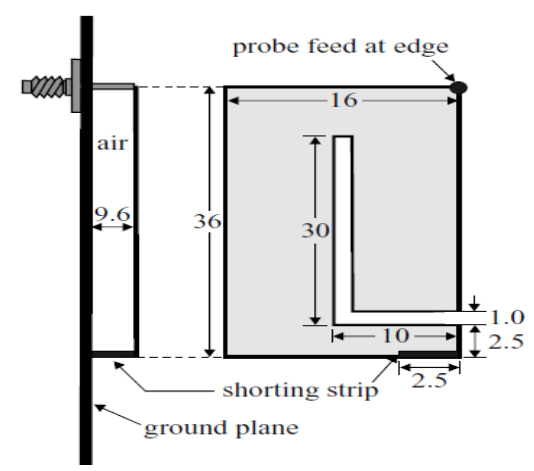

Fig 5: probe-fed shorted patch antenna operated at dual band [5]. 


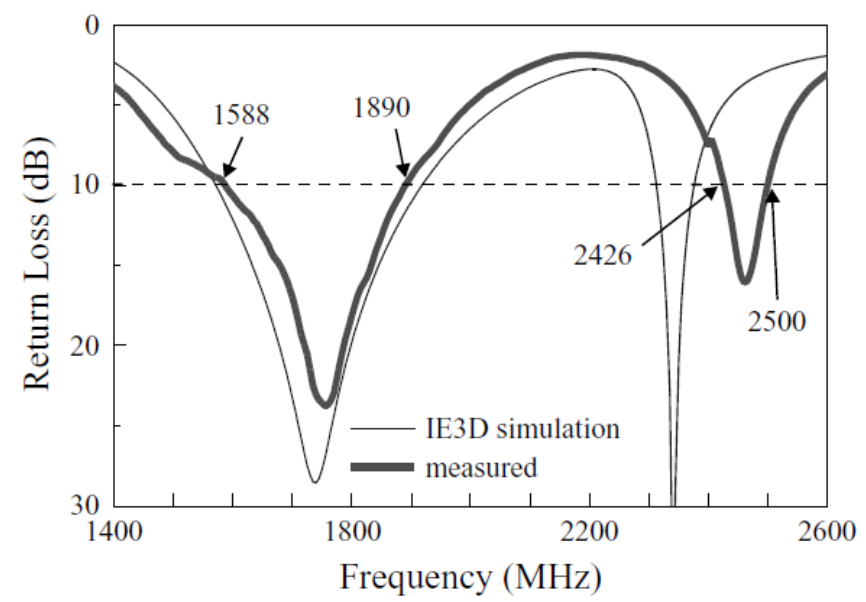

Fig 6: Return loss versus frequency plot for figure 5[5]

\section{COMPACT AND BROADBAND MICROSTRIP ANTENNA WITH STACKED SHORTED PATCH}

By using two stacked shorted patch and make both patches radiate equally as possible and making radiation quality factor as low as possible, one can achieve enhance impedance bandwidth for fixed antenna volume [6].

Design of a compact and broadband S-shaped microstrip antenna [8] is given below:

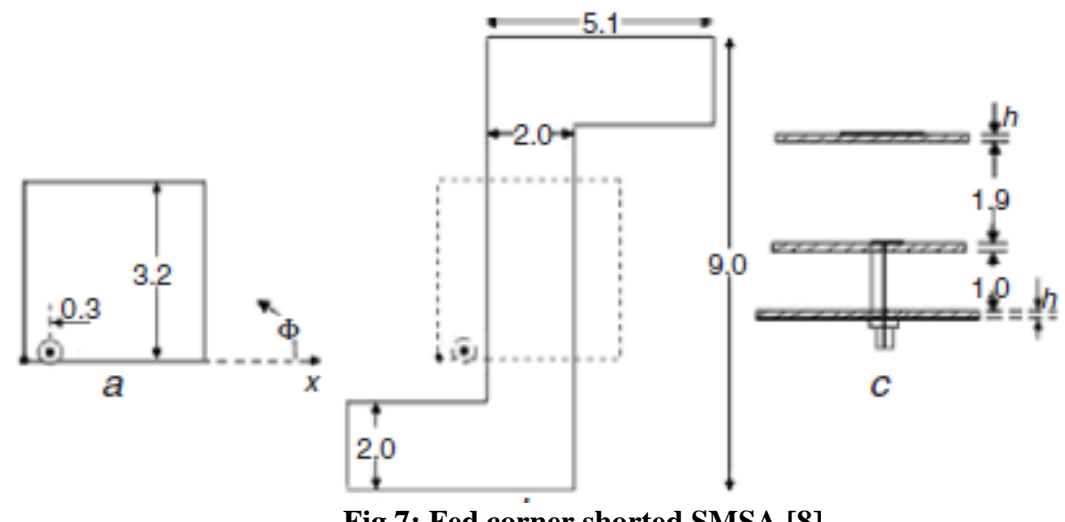

Fig 7: Fed corner shorted SMSA [8]

The proposed broadband S-shaped MSAs, uses stacked configuration with a corner shorted square MSA (SMSA) or by cutting a resonant $\mathrm{S}$-shaped slot inside the S-shaped MSA. The BW is increased by using either multi-resonator gapcoupled and stacked configurations or by cutting a resonant slot inside the patch $[6,7]$. The gain S-shaped MSA is better than compared to the C-shaped MSA [8]. The simulated and measured BWs are $108 \mathrm{MHz}(12.7 \%)$ and $118 \mathrm{MHz}(14 \%)$ [8]. S-shaped MSA is requires thicker substrate and can be reduced by using its stacked configuration with either a fed Sshaped MSA or a fed corner shorted SMSA, which will further add to the BW.
Another design of antenna is square shaped stacked patch with slots and two walls at the edge yields the bandwidth of $76.25 \%$ at frequency $4.95 \mathrm{GHz}$ to $11.05 \mathrm{GHz}$ the input VSWR is $<2 .-14 \mathrm{~dB}$ is the minimum return loss. The dimension of the proposed antenna is $\mathrm{h} 1 \quad(2.524 \mathrm{~mm}), \mathrm{h} 2(5.75 \mathrm{~mm})$, permittivity of the lower substrate(5.4), permittivity of the upper substrate(4), loss tangent of lower substrate for h1(0.002), loss tangent of lower substrate for h2(0.02), $\mathrm{L}(20 \mathrm{~mm}), \mathrm{L} 1(5 \mathrm{~mm})$, size of the square $\operatorname{slot}(2 \mathrm{mmX} 2 \mathrm{~mm})$ 


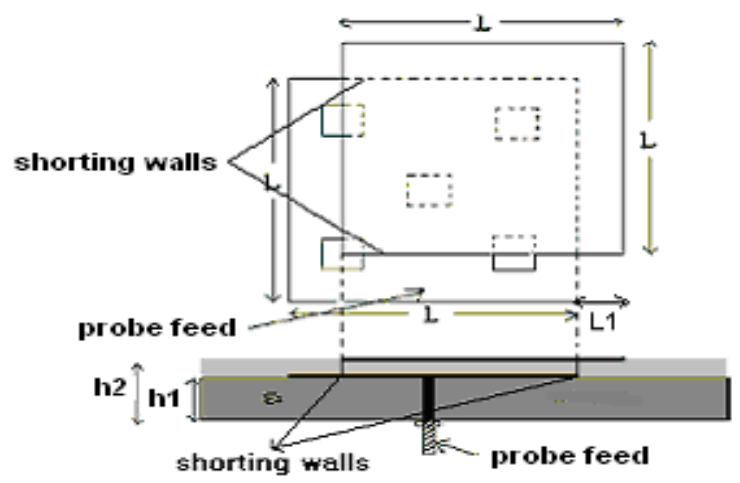

Fig 8: Design of shorted post antenna [9]

\section{COMPACT AND BROADBAND MICROSTRIP PATCH ANTENNA WITH SLOT-LOADING}

In this technique a slot is implanted on the radiating patch of microstrip antenna, which leads to wider bandwidth while keeping the size small [10]. Slot increases the current path length on patch which increases the bandwidth and reduces the size. A triangular patch [11] using this technique is shown in figure (9). Two branch-like slots are made on the radiating patch. First two broadside-radiation modesTM10 andTM20 of the triangular microstrip antenna can be perturbed such that their resonant frequencies are lowered and close to each other to form a wide impedance bandwidth [11].

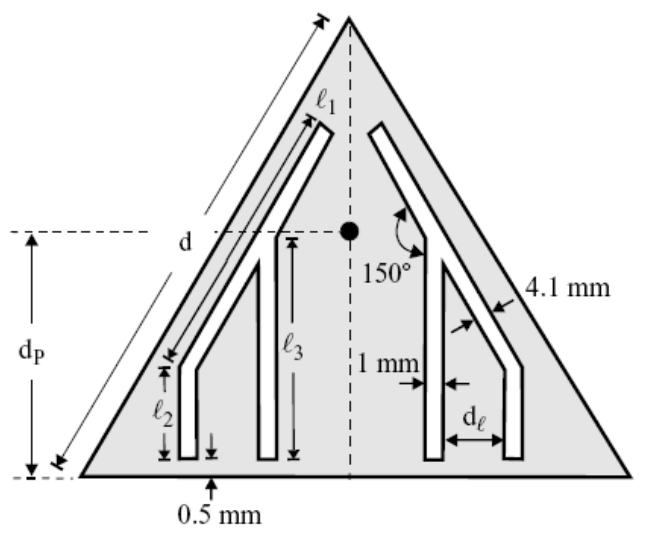

Fig 9: Slot loaded Triangular Microstrip Patch Antenna [10].

Impedance bandwidth achieved by this design is three times to that of regular triangular microstrip patch antenna and size reduction is about $25 \%$ [10].

Another study of rectangular-slot-loaded and V-slot-loaded proximity-coupled microstrip antennas is reported and results

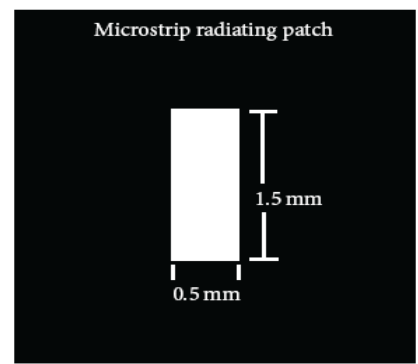

Fig 10: Rectangular-slot-loaded and V-slot-loaded proximity-coupled microstrip antennas [12].

All these measurement and calculations are done by using IE3D software. Comparison between simulated and measured return losses Rectangular-slot-loaded and V-slot-loaded

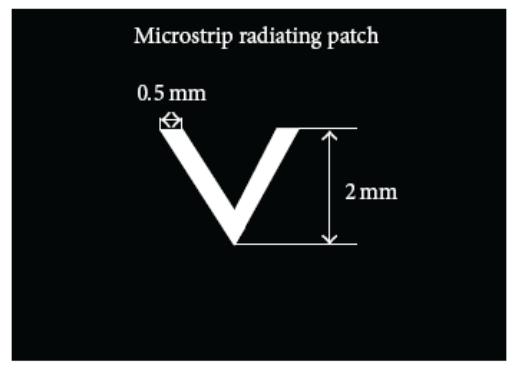

are verified by measurement [12]. Results verify that this antenna is with compact size and wider bandwidth. Figure (10) shows the geometry of both rectangular and V-slot loaded microstrip patch antenna.

proximity-coupled microstrip antennas are shown below in figure (11) and figure (12) respectively. 


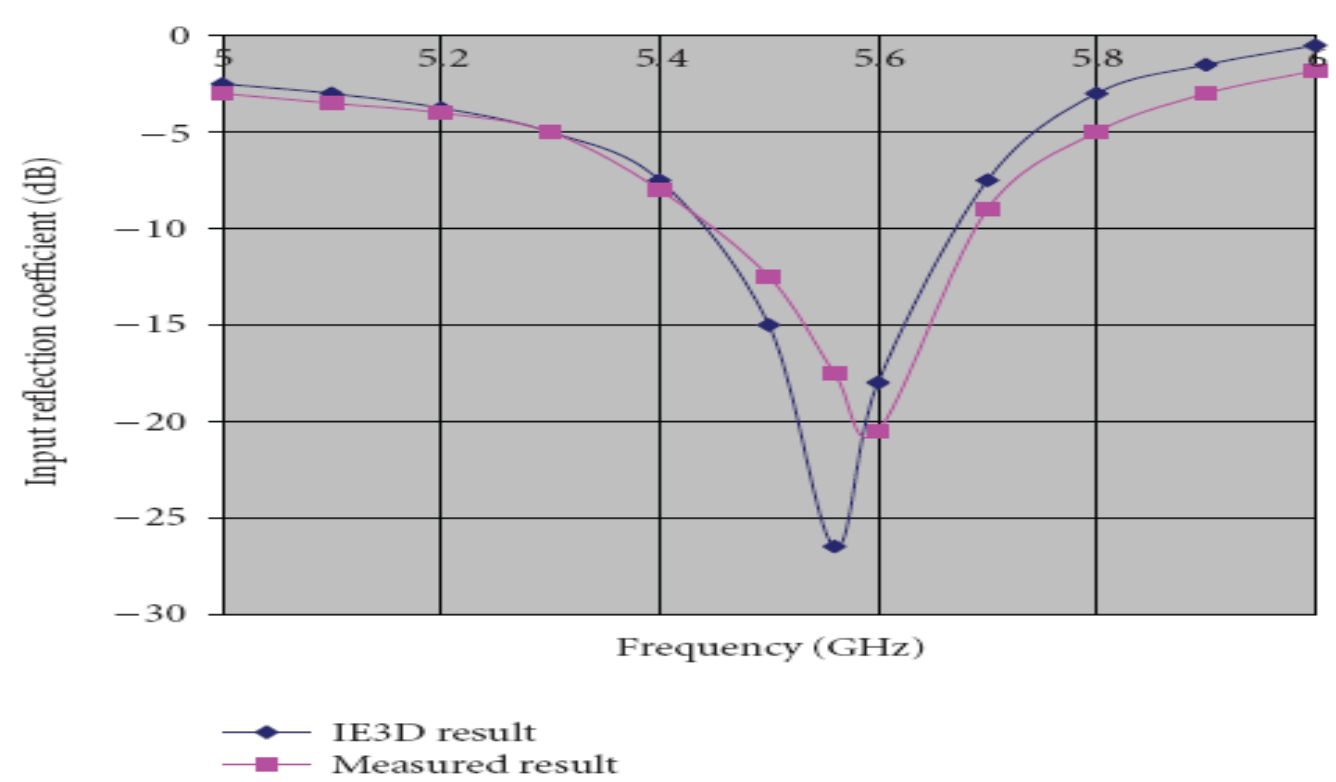

Fig 11: Comparison between simulated and measured return losses for rectangular-slot-loaded Proximity coupled microstrip antenna [12].

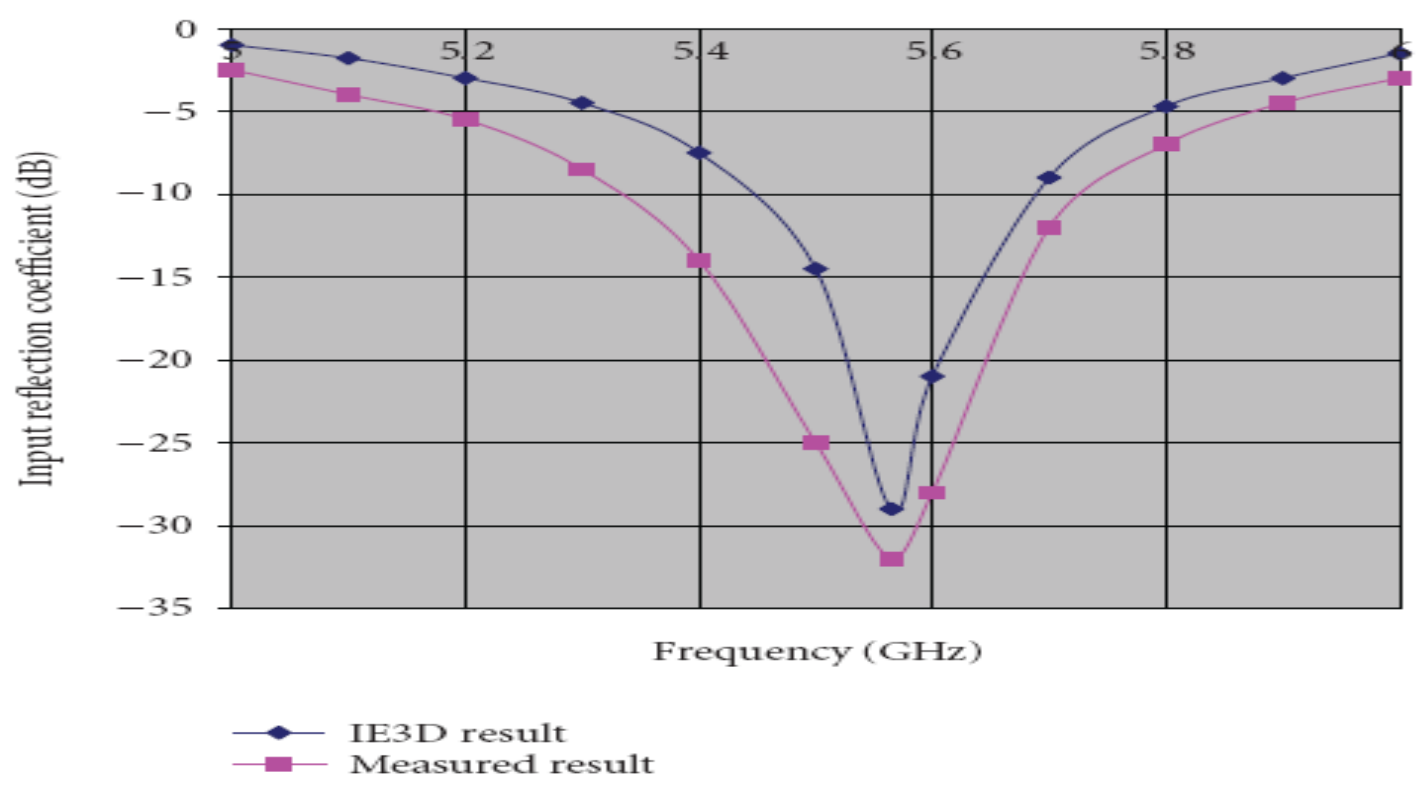

Fig 12: Comparison between simulated and measured return losses for V-slot-loaded proximity-coupled microstrip antenna [12].

The proposed rectangular-slot-loaded proximity-coupled microstrip antenna the peripheral area of the patch is reduced by $65 \%$ and using V-slot-loaded proximity-coupled microstrip antenna the peripheral area of the patch is reduced by $60 \%$ [12]. Impedance bandwidth of V-slot-loaded microstrip antenna is higher than rectangular-slot-loaded microstrip antenna.

\section{COMPACT AND BROADBAND MICROSTRIP PATCH ANTENNA WITH SLOTTED GROUND PLANE TECHNIQUE}

In this technique a slot is made on ground plane of microstrip antenna. By increasing the length of slot impedance bandwidth can be increased. As slotted patch increases the current path length same can be applied to the ground plane. Design of a compact and broadband microstrip patch antenna with slotted ground [13] was proposed by J. S. Kuo. Here 
three identical slots are made on ground plane aligned with

equal spacing.

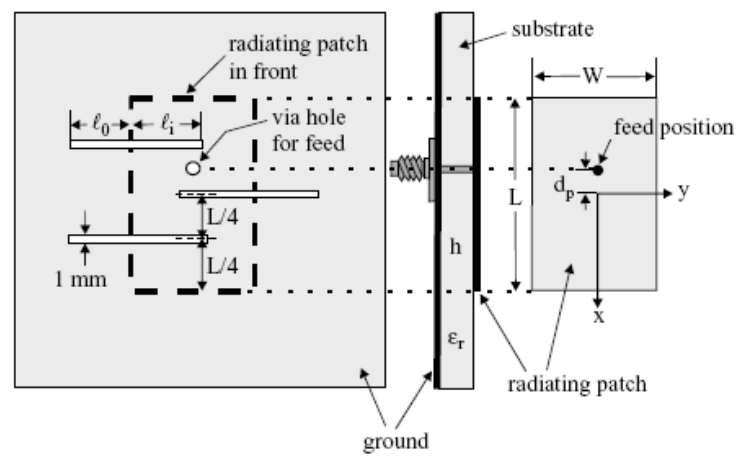

Fig 13: Design of compact microstrip antenna with meandering slots in the ground plane [13].

This configuration produces an antenna with size reduction of 56\%; it also leads to increased bandwidth [13].

Another design for slotted ground plane [14] can be generated by embedding pair of narrow slots; these slots are perpendicular to the antenna's resonant direction. Size reduction of about $39 \%$ is achieved in this configuration, design is given below:

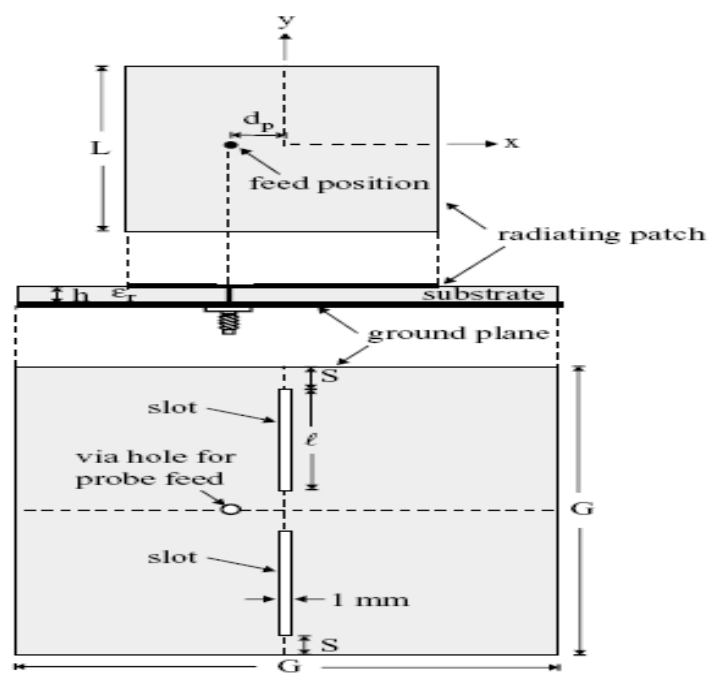

Fig 14: Configuration of compact microstrip antenna with slotted ground [14].

Another related design to slotted ground [15] yields wider bandwidth up-to three times to that of a conventional one and $60 \%$ reduced size. This technique depends on exciting two modes with close resonant frequencies.

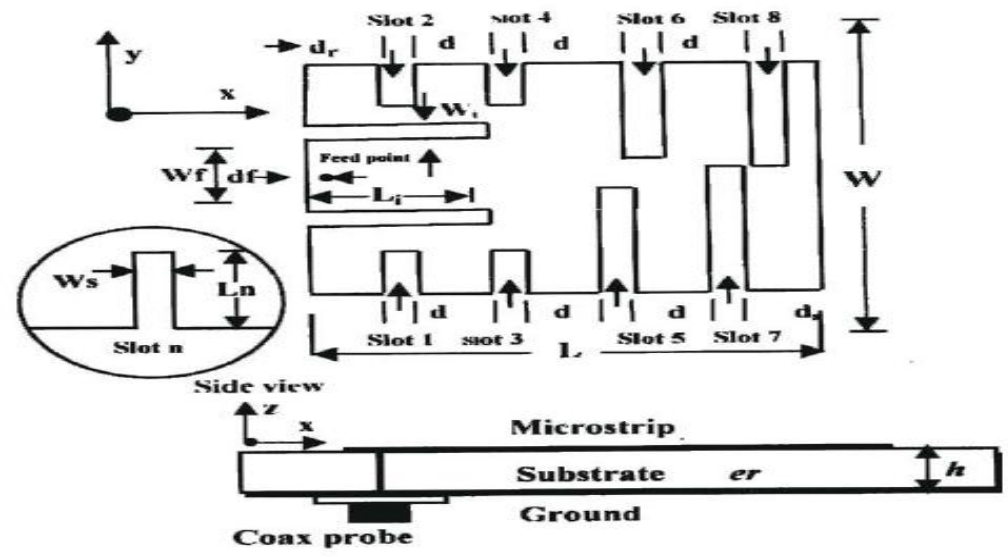

Fig 15: Configuration with four slits on the patch [15].

This proposed design produce wider bandwidth than conventional microstrip antenna.
All these above discussed techniques produce compact size antenna with wider bandwidth, which is suitable for any hand held devices. 


\section{TABLE FOR THE COMPARATIVE ANALYSES OF BROADBAND AND COMPACT TECHNIQUES:}

\begin{tabular}{|c|c|c|c|}
\hline S.NO & Broadband and compact Techniques & Configuration & Remarks \\
\hline \multirow{3}{*}{1.} & \multirow{3}{*}{ Shorted Patch Technique } & Shorted patch for GPS antenna & $\begin{array}{l}\text { Size reduction is } 24.6 \% \\
\text { achieved when compared with } \\
\text { conventional antenna }\end{array}$ \\
\hline & & $\begin{array}{l}\text { Broadband antenna for IMT-2000 } \\
\text { mobile set }\end{array}$ & $\begin{array}{l}\text { Bandwidth achieved is } 17.8 \% \\
\text { with } 1.862-2.225 \quad \mathrm{GHz} \\
\text { frequency }\end{array}$ \\
\hline & & Rectangular microstrip patch & $\begin{array}{l}\text { Yields bandwidth of } 17.4 \% \text { at } \\
1.8 \mathrm{GHz} \text { frequency and } 3 \% \text { at } \\
2.4 \mathrm{GHz} \text { frequency }\end{array}$ \\
\hline \multirow[b]{2}{*}{2.} & \multirow[b]{2}{*}{ Stacked Shorted Patches Technique } & S-shaped stacked patch & $\begin{array}{ll}\text { Yields Simulate bandwidth of } \\
12.7 \% \text { and } \\
\text { bandwidth of } 14 \%\end{array}$ \\
\hline & & Square shape stacked patch & $\begin{array}{l}\text { Yields Bandwidth of } 76.25 \% \\
\text { at frequency } 4.95 \mathrm{GHz} \text { to } \\
11.05 \mathrm{GHz} \text { the input VSWR is } \\
<2 \text {. Return loss IS }-14 \mathrm{~dB}\end{array}$ \\
\hline \multirow{3}{*}{3.} & \multirow{3}{*}{ Slot-Loading Technique } & Triangular patch & $\begin{array}{l}\text { Achieved Impedance } \\
\text { bandwidth is three times to } \\
\text { that of regular triangular } \\
\text { microstrip patch antenna and } \\
\text { size reduction is about } 25 \%\end{array}$ \\
\hline & & Rectangular slot loaded & $\begin{array}{l}\text { Size reduced by } 65 \% \text { and } \\
\text { impedance bandwidth is less } \\
\text { than V slot }\end{array}$ \\
\hline & & V slot loaded & $\begin{array}{l}\text { Size reduced by } 60 \% \text { yields } \\
\text { impedance bandwidth higher } \\
\text { than rectangular patch }\end{array}$ \\
\hline \multirow{3}{*}{4.} & \multirow{3}{*}{ Slotted Ground Plane Technique } & Microstrip antenna with Meandering slot & $\begin{array}{l}\text { Size is reduced by } 56 \% \text { and } \\
\text { increased bandwidth }\end{array}$ \\
\hline & & $\begin{array}{l}\text { Compact microstrip antenna with slotted } \\
\text { ground }\end{array}$ & Size reduced by $39 \%$ \\
\hline & & Configuration of four slit on the patch & $\begin{array}{l}\text { Bandwidth achieved is } 3 \\
\text { times greater than the } \\
\text { conventional one and size } \\
\text { reduced by } 60 \%\end{array}$ \\
\hline
\end{tabular}

\section{CONCLUSION}

Bandwidth enhancement and size reduction are becoming major design considerations for practical applications of microstrip antenna. Many techniques have been used to achieve wideband and to reduce the size of microstrip antennas. This paper shows the review and survey of various such techniques. Out of all techniques shown above in this paper Slot-Loading Technique and Slotted Ground Plane Technique yields maximum bandwidth and compact in size.

\section{ACKNOWLEDGMENT}

The Authors would like to thank Dr. Sandip Vijay and Dr. Sonika Singh for their encouragement and support in this work.

\section{REFERENCES}

[1] Abdelaziz A. Abdelaziz and Dalia M. Nashaat, "Compact GPS Microstrip Patch Antenna," Journal of Theoretical and Applied Information Technology, ISSN 1817-3195/ ISSN 1992-8645, 2008.

[2] Y. J. Wang and C. K. Lee, "Compact and Broadband Microstrip Patch Antenna For The 3g IMT-2000 Handsets Applying Styrofoam And Shorting-Posts," Progress In Electromagnetic Research, PIER 47, 75-85, 2004.

[3] Pradeep Kumar, G. Singh, "Microstrip Antennas Loaded with Shorting Post," SciRes (http://www.SciRP.org/journal/eng/), June 2009.

[4] K. L. Wong and W. S. Chen, "Compact microstrip antenna with dual-frequency operation," Electronics Letters, Vol. 33, No. 8, pp. 646-647, 1997. 
[5] K. L. Wong and W. S. Chen, "Compact microstrip antenna with dual-frequency operation," Electronics Letters, Vol. 33, No. 8, pp. 46-47, 1997.

[6] K. L. Wong and W. S. Chen, "Compact microstrip antenna with dual-frequency operation," Electronics Letters, Vol. 33, No. 8, pp. 54, 1997

[7] K Usha kiran, Ravi M Yadahalli, at el, "Compact Broadband Stacked Dual Wide Slit Loaded Rectangular Microstrip Antenna," Indian Journal Of

[8] Radio And Space Physics, vol. 37, pp. 366-369, October 2008

[9] A.A. Deshmukh and G. Kumar, "Compact Broadband SShaped Microstrip Antennas" Electronics Letters, Vol. 42, no. 5, 2 March 2006.

[10] P.K.Singhal, Bhawana Dhaniram, and Smita Banerjee, "A Stacked Square Patch Slotted Broadband Microstrip Antenna," Journal of Microwaves and Optoelectronics, Vol. 3, No. 2, August 2003.

[11] Kin-Lu Wong, "Compact and Broadband Microstrip Antennas", John Wiley \& Sons, page number: 78-83, ISBNs: 0-471-41717-3, 2002
[12] S. T. Fang, "Analysis and design of triangular microstrip antennas," Ph.D. dissertation, Department of Electrical Engineering, National Sun Yat-Sen University, Kaohsiung, Taiwan, 1999.

[13] Jibendu Sekhar Roy and Milind Thomas, "Compact and Broadband Microstrip Antennas for Next Generation High-Speed Wireless Communication Using HIPERLAN/2," International Journal of Microwave Science and Technology, Volume 2007, Article ID 75320, doi:10.1155/2007/75320.

[14] J. S. Kuo and K. L. Wong, "A compact microstrip antenna with meandering slots in the ground plane," Microwave Opt. Technol. Lett. 29, 95-97, April 20, 2001.

[15] T. W. Chiou and K. L. Wong, "Designs of compact microstrip antennas with a slotted ground plane," in 2001 IEEE Antennas Propagat. Soc. Int. Symp. Dig. pp. 732735 .

[16] Soliman A. Shetawy et al., "Slotted Ground Plane of Rectangular Patch Microstrip Antenna with Enhanced Bandwidth and Size Reduction," International Conference on COMMUNICATIONS, ISBN: 978-9606766-84-8, July 23-25, 2008 